\title{
Imaging of Coronary Arteries Aid in Prevention of Atherosclerosis and Clinical Coronary Heart Disease
}

\author{
Lewis H. Kuller ${ }^{*}, 1$ and Daniel Edmundowicz ${ }^{2}$ \\ ${ }^{I}$ Department of Epidemiology, Graduate School of Public Health, University of Pittsburgh, Pittsburgh, PA, USA \\ ${ }^{2}$ UPMC Cardiovascular Institute \& Department of Medicine, University of Pittsburgh, Pittsburgh, PA, USA
}

\begin{abstract}
Prevention of progression of atherosclerosis is the best approach to reduce incidence of myocardial infarction, sudden coronary heart disease (CHD) death, stroke and peripheral vascular disease. Research over the past 40 years has identified the risk factors for atherosclerotic disease, noninvasive methods for measuring the extent of atherosclerosis in multiple vascular beds and very efficacious therapy to reduce the level of risk factors and prevent cardiovascular diseases. Cardiovascular incidence and death rates have declined. Nevertheless, rates of CHD and other vascular disease remain much higher in many countries and within select regions of certain countries than necessary. Prevention of atherosclerosis depends on 4 key steps: 1) a much more aggressive effort to lower modifiable risk factors, especially apolipoprotein-B (ApoB)-containing lipoproteins, low density lipoprotein (LDL) particles, LDL cholesterol, blood pressure, obesity, and smoking during adolescence and young adult years; 2) identify and treat elevated ApoB lipoproteins, diabetes and smoking cessation of very high risk young adults as early as possible; 3 ) use of imaging to identify atherosclerosis of coronary and other arteries for appropriate segments of the adult population and treatment of risk factors for those with identifiable atherosclerosis; and 4) improved approaches to deliver prevention of cardiovascular disease to large numbers of asymptomatic individuals identified by non invasive imaging to maximize adherence to therapies. The major missing piece is better methods to identify vulnerable coronary plaques on the verge of an atherothrombotic transition and better treatments to prevent "acute" events. However, the four steps above will still lead to very substantial reductions in CHD incidence and mortality.
\end{abstract}

Keywords: Coronary artery calcium, prevention, screening.

\section{INTRODUCTION}

We believe that the prevention of atherosclerosis is the goal for the reduction of incidence of most clinical coronary heart disease (CHD), myocardial infarction (MI) and angina and deaths due to CHD as well as other cardiovascular events $[1,2]$. The task at hand is to improve the primary prevention of atherosclerosis; delay its progression and prevent atherothrombosis. The paradigm has now shifted to identifying and preventing heart attack over the lifetime of an individual [3]. Most current short term, i.e. 10 years, risk scoring systems identify only a relatively small percentage of all future heart attack victims as "at risk" candidates for lipid lowering therapy $[4,5]$.

Advances in epidemiology, clinical and animal experimental studies have documented the determinants of the risk of atherosclerosis and CHD across many populations. Levels of apolipoprotein B (ApoB) lipoproteins, blood pressure (BP), smoking, high density lipoprotein (HDL), ApoA $A_{1}$, obesity, diabetes and physical inactivity are the primary determinants of the risk of CHD [6]. Modification of these risk factors decreased the risk of CHD in clinical trials or in large observational studies [7-9].

*Address correspondence to this author at the Department of Epidemiology, GSPH, University of Pittsburgh, 550 Bellefield Professional Building, 130 North Bellefield Avenue, Pittsburgh, PA 15261, USA; Tel: 412-383-1895; Fax: 412-383-1956; E-mail: kullerl@edc.pitt.edu
The CHD and cardiovascular disease (CVD) incidence and death rates dramatically declined in the United States and other countries but remain much higher in the United States compared to Japan, France and Italy $[10,11]$. Countries with lower rates of CHD mortality and incidence have less prevalence of coronary atherosclerosis $[12,13]$. The same risk factors are determinants of CHD among countries $[14,15]$. In countries with low CHD rates in spite of similar levels of traditional risk factors or in countries with higher rates, there are likely unique lifestyle factors that are protective against atherosclerotic disease.

\section{IS CHD PREVENTABLE?}

Epidemiological studies have identified individuals who are at extremely low lifetime risk of CHD $[6,16]$. Unfortunately, very few individuals, perhaps $<10 \%$ of the population, meet low risk criteria, i.e. low blood cholesterol, $\mathrm{BP}$, nonsmoking, no diabetes. Furthermore, the percentage of the population at low risk based on these criteria is not increasing over time [17-19]. The majority of the adult United States population and in many other countries have extensive atherosclerosis beginning at an early age such that by $60-65+$ the majority of men and most women have extensive atherosclerotic disease as measured in vivo by various markers of subclinical atherosclerosis, i.e. coronary calcium, carotid intima media thickness (IMT), decreased ankle-brachial BP, or at postmortem examination. The development of atherosclerosis is not "normal" aging [2024]. 
The total atherosclerotic burden is the primary determinant of incident clinical CHD [16, 25]. MI, angina and sudden CHD death represent end-stage coronary atherosclerosis characterized by changes in plaque morphology and thrombosis [26, 27]. The incubation period for development of atherosclerosis begins in childhood, progresses over time and is determined primarily by levels of ApoB lipoproteins in the setting of other risk factors that increase endothelial vulnerability to lipoproteins and secondary inflammatory changes [16, 28-30].

Key risk factors, such as total and low density lipoprotein cholesterol (LDL-C) and BP, are "normally distributed" in the population and risk of disease is a linear function of risk factor levels from total serum cholesterol $150-160 \mathrm{mg} \%$ or systolic BP (SBP) $\geq 120 \mathrm{mmHg}$ [31]. A high percentage of the adult United States population are candidates for pharmacological or lifestyle modifications to lower risk factor levels. There are estimated to be over 35 million with LDL-C $>130 \mathrm{mg} \%$, 70 million with $\mathrm{BP} \geq 140 / 90 \mathrm{mmHg}$ in the US adult population and even higher numbers are candidates for therapy if we accept "high" levels to be defined as LDL-C $\geq 100$ and SBP $\geq 120 \mathrm{mmHg}$ [30]. Most of the heart attacks occur among individuals with "average" level of risk factors, not very high levels because of the much higher percentage of individuals that are classified as intermediate or low risk factor levels. The absolute risk for an individual is directly related to level of their risk factors. For example, the Framingham Heart Study reported that $35 \%$ of heart attacks occurred among individuals with serum cholesterol $\leq 200 \mathrm{mg} \%$ [31]. Similarly, in the Multiple Risk Factor Intervention Trial (MRFIT) of nondiabetic men age 35-39 at baseline and 16 years of follow up, $24 \%$ of subsequent CHD deaths occurred among men with serum cholesterol $\leq 200 \mathrm{mg} \%$ and $60 \%$ with serum cholesterol $\leq 240$ $\mathrm{mg} \%$, the latter 2 groups representing $77 \%$ of the MRFIT study population [32].

Populations with a low prevalence of atherosclerosis have very low CHD incidence and mortality. Individuals with very low coronary calcium scores, a marker of a low atherosclerotic burden have extremely low subsequent risk of clinical CHD [33-35].

Individuals with extensive coronary atherosclerosis may survive years without incident heart attack. Changes in plaque morphology induced by inflammation, and other factors leading increased vulnerability and risk of thrombogenesis and, in part, determine the immediate risk of incident CHD given the extent of atherosclerosis. The incubation period of conversion of atherosclerosis to clinical events can be very short - instantaneous sudden CHD death in asymptomatic individuals due to plaque erosion, rupture, thrombosis, and intra-plaque hemorrhage is well described $[36,37]$. Importantly, the short term prediction of the risk of a heart attack in any individual, the exact time of plaque rupture, erosion or thrombosis cannot be measured in the population. Pathology studies show that rupture and erosion of plaques without clinical events may be very common [38]. Indeed, the amount of coronary atherosclerosis provides an excellent estimate of the population risk of developing clinical CHD but does not tell when any single individual within the population will have a heart attack or under what circumstances this is likely to occur, such as during exercise, work, eating, stressful life events, etc.

Some investigators have wrongly concluded that without a better understanding of arterial biology, aggressive preventive approaches have limited benefit. They incorrectly postulate that if we could better discriminate individuals by the characteristics of atherosclerotic plaque, thrombogenesis, or fibrinolysis, then a smaller number of these individuals might require intensive pharmacological therapies to prevent thrombosis and heart attack.

This situation is analogous to the development of the polio vaccine. Only 1/1, 000 individuals infected with polio virus developed paralytic disease [39]. For many years prior to the Salk vaccine trials, major research efforts were directed at an attempt to identify the specific characteristics of individuals infected with the virus that would develop paralytic disease thus allowing the restriction of vaccine to a small subsample; perhaps 1/1, 000 infected individuals. The effective preventive approach with the Salk vaccine required vaccination of the entire population. The number needed to vaccinate to prevent one case was very high and adverse effects of the vaccine occurred given the large number of individuals vaccinated, especially early in the vaccine use [40]. Many argued then that without identifying the specific determinants of the tissue response to the virus, i.e. virulence, a vaccine was not feasible. This was clearly a wrong concept. Similarly, prevention of atherosclerotic disease has to be the key to substantially reducing the risk of clinical CHD. While we do not yet have a vaccine to prevent atherosclerosis, it is clear that very low levels of key risk factors in a population results in minimal prevalence of atherosclerosis and a low incidence of clinical CHD.

Therapeutic interventions at the time of a heart attack or secondary prevention after a heart attack have been effective in reducing morbidity and mortality $[41,42]$. The majority of heart attack deaths still occur outside of the hospital and probably close to $20 \%$ of first heart attacks, especially in men, are sudden unexpected deaths. The current therapies for secondary prevention after heart attack substantially reduce risk of recurrent CHD and death in those to whom they can be applied [43-45]. The risk of CHD remains substantially higher than for primary prevention of incident clinical CHD and much higher than for those individuals classified as low risk of CHD. Acute treatments and secondary prevention are effective but will not solve the huge disability and costs of CVD. Primary prevention of atherosclerosis and its progression is the key to reducing CHD incidence and mortality and would have a major impact on health care costs for CVD, currently the most costly component of health care [46].

\section{APPROACHES TO PREVENTING CVD}

The key question now is how to implement a more effective primary prevention effort. There are at least 5 approaches to further reduce CVD incidence and mortality, two primarily for younger and three for older individuals. First, CHD is a common source epidemic due to adverse diet and lifestyle habits. We should apply a broad-based public health approach to prevent the increasing incidence with age and reduce the average level of risk factors and progression of atherosclerosis for the total population irrespective of 
individual risk factor levels. The goal would be to modify the diet of the population so that average LDL-C or ApoB would be below 70 or $100 \mathrm{mg} \%$, SBP $<120 \mathrm{mmHg}$ and also achieve tobacco cessation in a majority of the population, especially below the age of 40 or 50 [47]. Clinical CHD would then become a low incident and mortality disease and health care costs for treating CHD will likely decrease substantially. Unfortunately, we have only been partially successful in implementing a public health approach. For example, the $75^{\text {th }}$ percentile for LDL-C for teenagers in the United States is over $100 \mathrm{mg} \%$, i.e. $25 \%$ are at higher risk of atherosclerosis and $20 \%$ are cigarette smokers, assuring a continuing epidemic of CHD [48]. Improving "primordial prevention" of risk factors beginning in childhood by lifestyle-environmental modifications is an important goal which requires major changes in food processing, public health education and consumer behavior [49]. Primary prevention beginning in childhood or adolescence will have little impact on the current adult populations ages $50+$ years that already have atherosclerotic disease and high risk of clinical CHD. Efficacious individualized preventive strategies must therefore remain a high priority.

Second, individualized nonpharmacological interventions may have their biggest impact at younger ages less than 40 in preventing the rise in risk factors with age and subsequent development and progression of atherosclerosis, i.e. primordial prevention. The extent of risk factor lowering, i.e. ApoB, LDL-C, may be less to prevent atherosclerosis or early progression than required to prevent heart attacks for individuals with more extensive atherosclerosis [50]. For example, it is possible to identify younger individuals with low short term but high lifetime risk [51]. An aggressive individualized primary prevention effort to lower risk factors to "ideal risk," such as LDL-C $<100 \mathrm{mg} \%$, SBP $<120$ $\mathrm{mmHg}$ and especially smoking cessation, could have a major impact on lifetime risk. Such a nonpharmacological approach has been extremely difficult to implement for most of the population, especially less educated and lower socioeconomic status members.

There are three approaches for preventing heart attacks for individuals age 40 or $50+$ who already have elevated risk factors and evolving atherosclerosis. First is the traditional risk assessment beginning usually for men at ages40-50 and women age 50-60 and then implementing pharmacological and nonpharmacological therapies based on 10-year, risk score such as the Framingham risk score (FRS) as utilized by the current Adult Treatment Panel (ATP) III guidelines in the United States and similar guidelines in other countries [52]. This approach has shortcomings that can be improved by including longer term risk prediction beyond the traditional 10 years of current guidelines and/or including a wider list of $\mathrm{CV}$ outcomes as endpoints to increase the percent of population at high risk, i.e. $20 \%$ risk, of broader CHD diagnoses or cerebral vascular disease rather than hard "CHD events" or reducing the level of risk percent to institute pharmacological therapy, i.e. high risk redefined as 10 or $15 \%$ risk of heart attack at 10 years rather than the $20 \%$. Unfortunately, most of these new methods still are likely to identify only $50-60 \%$ of potential heart attack victims as "at risk" requiring pharmacological therapies prior to heart attack. A large number of individuals destined to have a heart attack will not be candidates prior to heart attack for effective pharmacological therapy.

The lifetime risk of clinical CHD is very high. A key report evaluated the distribution of 10 -year and lifetime risk of CVD in US adults [53]. Only the traditional risk factors were evaluated, including SBP, total cholesterol, diabetes mellitus and cigarette smoking. If all risk factors were low, lifetime risk at age 50 for future CHD was only $5 \%$ for men and $8 \%$ for women. Only $8.4 \%$ of men and $14.3 \%$ of women are at ideal risk. If even 1 risk factor was not optimal, lifetime risk increased to $38 \%$ for men and $27 \%$ for women and if 1 risk factor was actually elevated, lifetime risk was almost 50\% in men and 39\% for women. Most important, $50 \%$ of individuals classified as low short term risk based on the FRS had a high lifetime risk of CHD. The important question, therefore, is whether we should implement the very efficacious lipid lowering and antihypertensive therapies for the majority of men and women with high lifetime risk irrespective of their short term risk rather than the present approach which focuses on individuals with high short term risk.

Fourth is measuring the extent and characteristics of subclinical atherosclerosis using computed tomography (CT) of the coronary arteries, carotid ultrasound or even possibly magnetic resonance imaging (MRI) of the coronary and carotid arteries [54, 55]. Treatment of risk factors would be based on extent of subclinical disease. Individuals with lower levels of risk factors but extensive atherosclerosis are probably "genetically susceptible" and would still have risk factors further reduced. Numerous epidemiological studies over the past 20 years have not identified any important new risk factors in the causal pathway for atherosclerosis and incident CHD. It remains possible that other undetected risk factors are primary determinants of atherosclerosis [56, 57]. Recently identified risk factors [58] either identify inflammation [59] in the atherosclerotic plaque or risk of thrombosis [60].

Fifth, provide a safe and cheap pharmacological preventive therapy for most adults, irrespective of their risk factor levels, beginning at younger ages, i.e. 30 s- 40 s, to reduce the level of the key risk factors early in life and prevent or slow the progression of atherosclerosis to clinical CHD - the so called "polypill approach" for reducing CHD incidence and mortality [61]. Treating all adults who were not at low lifetime risk above would be at least equivalent to the polypill approach. This broad pharmacological approach should be the last resort or backup of our failure to successfully implement a population strategy to substantially reduce the levels of risk factors [10].

\section{WHICH RISK ASSESSMENT METHOD IS BETTER?}

The function of risk assessment is to segregate individuals into different risk stratums that provide guidelines for pharmacological and nonpharmacological therapies and for further diagnostic evaluations, i.e. exercise testing, nuclear and MRI imaging studies for the detection of myocardial ischemia, coronary angiography, etc. Risk assessment by itself cannot reduce the incidence of CHD. Actions, i.e. interventions, that are implemented following a risk assessment are the determinants of the reduction in risk 
of CHD. There is no gold standard or scientifically proven risk assessment method or risk score to define good or bad risk assessment. No risk assessment method has been shown in randomized clinical trials to lead to a reduced incidence of CHD as compared to an alternate approach for the reason stated above. Therefore, a key question is which method or methods are most likely to identify the highest percentage of individuals at risk of a heart attack and, at the same time, successfully identify lower risk individuals who do not need pharmacological or even expensive nonpharmacological therapies.

The clinical "trigger" for the initiation of pharmacological therapy is determined by 4 factors: 1) the scientific evidence that a specific risk factor level is associated with the increased risk of a disease, i.e. CHD, CVD. Most risk factors such as ApoB lipoproteins and SBP, are linearly related to the risk of CHD across their usual distribution in the population $[8,62]$. The risk factors are often normally distributed with little evidence of "bimodality," etc. The differences in distribution of risk factors, i.e. BP, cholesterol, between those who do or do not get disease are small, with substantial overlap of levels of risk factors between the populations. Cutpoints are therefore arbitrary; 2) the evidence that a specific intervention such as lowering blood ApoB lipoproteins will reduce the incidence of CHD or CVD, and the consistency of such evidence across populations, race and sex groups [63]. Evidence that at a specific level of the risk factor or the magnitude of the change in risk factors by pharmacological, i.e. high versus low dose statins, etc., reducing SBP to $\leq 130 \mathrm{mmHg}$, or nonpharmacological intervention will be directly related to reduction of the incidence of CHD [64, 65]. Most clinical trials now suggest that at least a $30-40 \%$ reduction in LDL-C or ApoB may be required to demonstrate any significant reduction in the risk of clinical CHD [52, 66], especially among middle-aged and older individuals likely to have extensive underlying atherosclerosis. This has major implications because the nonpharmacological approach rarely can reduce LDL-C or ApoB by this magnitude over the long term for most participants in a program. Controversy continues as to whether lowering SBP below $130 \mathrm{mmHg}$, further reduces risk of stroke and renal disease, especially CHD, or whether treatment of diabetes will reduce risk of CHD.

3) The cost of the technology for the risk assessment, such as measurement of LDL-C, ApoB or LDL particles (LDL-P), oxidized LDL, BP or 24-hour BP or central BP measurement or measurement of coronary calcium or carotid ultrasound, etc. measured both as costs of measurement and potential follow up testing effects, exposure to expensive diagnostic tests [67]. A large number of individuals need to be screened in order to identify the relatively few who will develop incident CHD at least over the short term. Any screening technology must be relatively low cost and safe when applied to large numbers of individuals. This will usually require technology that is automated, can be administered by technicians and also include automated computerized readings that can be done by well-trained technicians. Screening is not a diagnostic procedure. Measuring ApoB or coronary calcium is not very useful in defining heart attack versus no heart attack in a patient presenting with severe chest pain to rule out MI [67].
4) The costs of the specific interventions, given that screening identifies an individual at risk, are of two types: a) monetary cost of the specific intervention, i.e. the cost of lipid lowering drugs, antihypertensive therapy, nonpharmacological therapies to reduce risk factors; and b) the cost of adverse events associated with the specific intervention, i.e. adverse effects of antihypertensive therapy, lipid lowering statin therapy $[68,69]$ as well as nonpharmacological therapies such as injuries associated with exercise, sudden death during an exercise program, depression and suicide following weight loss programs, etc. [70].

The decision level, i.e. the FRS or level of coronary calcium, carotid IMT, etc., that results in pharmacological versus nonpharmacological therapies is based on the above 4 factors. The decision level for treatment will change with results of new trials or other clinical research, i.e. identification of genetic host susceptibility. Clinical trials documenting the benefits of treating BP have changed guideline levels to begin antihypertensive drug therapy to lower initial BP levels [71]. This resulted in an increasing number of candidates for pharmacological therapy to lower their BP. The level of risk factors, such as BP, LDL-C, ApoB, are usually near normally distributed in the population. Therefore, there is a substantial increase in the number of individuals eligible for pharmacological therapy as the level of recommended therapy begins to move toward the mean or median of the population. A key element in this decision process is the comparative benefits of the pharmacological or surgical therapy versus nonpharmacological therapies to reduce the level of the risk factors and the incidence of clinical disease. Individualized preventive nonpharmacological therapies for lowering BP, LDL-C, reduction of body weight and even exercise are relatively ineffective in middle age and older individuals primarily because of lack of long term adherence to behavioral interventions and difficulties of individualized lifestyle modifications.

The cost of therapies, as noted, also becomes a key factor for determining the specific level to begin pharmacological therapy. The cost of lipid lowering drug therapies, such as statins, as well as BP therapies has declined dramatically over time. Pharmacological therapies are now relatively inexpensive and have a good long term safety track record although there are still adverse effects [72-75].

The decline in costs of drugs and long term safety and efficacy of drug therapy has changed the goals of risk assessment. High sensitivity, i.e. the ability of a risk assessment method to identify a very high percentage of individuals likely to develop a heart attack over long term, is of greater priority than specificity, misclassification as high risk. The polypill is an extreme example of pharmacological therapy for everyone irrespective of risk score and therefore "increases sensitivity" to close to $100 \%$ [61].

There is a strong positive association between risk scores such as the FRS and subsequent CHD events [76]. The cstatistic, a combination of sensitivity, i.e. to predict CHD, and specificity to predict no CHD, is often used as a measure of quality of a risk assessment method. The $\mathrm{c}$ statistic can be deceptive; a high c statistic can still result in many at-risk individuals, i.e. likely to have a heart attack and classified as 
not candidates for drug therapy [77]. The risk of CHD is continuous across range of risk factor levels. Arbitrary classification into 10 year low, intermediate and high risk to determine pharmacological therapies, results in many individuals who subsequently have a heart attack being initially classified as either low or intermediate risk and therefore not recommended for pharmacological therapies. Such individuals represent a failure of preventive therapies, especially among women $[17,78]$.

The short term risk prediction models led to a misconception that younger individuals and women, unless they have diabetes, are not at high risk of CHD [76, 77]. The higher risk candidates for pharmacological therapies consisted predominantly of older men and women with diabetes. A recent paper from the National Health and Nutrition Examination Survey (NHANES) 1999-2004 evaluation showed that no women age 35-44 years met the Framingham criteria of high risk, ( $>20 \%$ risk in 10 years) and only $0.6 \%$ of women aged $45-54$ years were high risk. The majority of women who have a first heart attack do not meet the criteria for being high risk or even intermediate risk based on the FRS [79].

A recent evaluation for risk scoring methods, such as the FRS, for CHD noted that the few randomized trials of risk scores and subsequent modification of risk factors showed no benefit on intermediate CHD outcomes. Furthermore, there is strong evidence that physicians do not use the risk scores $[80,81]$. Similar results have been noted in other countries. Another important question is whether knowledge of a "high risk" status actually changed behavior of those patients. The authors concluded that risk scoring was not necessarily associated with increased awareness or behavior changes [82-87].

\section{IMAGING OF ATHEROSCLEROSIS}

The extent of atherosclerosis is the most powerful determinant of the risk of clinical CHD based initially on studies of patients with suspected angina who had coronary angiography before the development and wide application of coronary bypass surgery [88]. Subsequently, peripheral measures of subclinical atherosclerosis, such as anklebrachial index [89, 90], carotid imaging [91], and CT to measure coronary calcium, were shown to be powerful predictors of the risk of CHD as was a composite measure of subclinical disease [92]. Quantification of the extent of coronary artery calcium has been documented to be a powerful predictor of the risk of clinical CHD independent of traditional risk factors [93-96]. A recent report from the American College of Cardiology and the American Heart Association supported computed tomography (CT) to measure coronary calcium as "reasonable" for asymptomatic adults at intermediate $10-20 \% 10$-year risk and at low to intermediate $6-10 \%$ risk but not for individuals with low $<6 \%$ risk [97]. The extent of coronary calcium is a strong and independent predictor of the risk of clinical CHD in men, women, middle-aged and very old, black, white, diabetic and nondiabetics. The association is continuous across levels of coronary calcium probably from a calcium score of 10 Agatston units or even less. Some investigators suggest that a coronary calcium score $\geq 100$ may be high risk and $\geq 400$ may be very high risk. Individuals with 0 coronary calcium scores are at very low risk of clinical CHD events [98].

The key question is whether the use of imaging technologies will improve prediction of CHD so that the majority of individuals likely or not likely to have a heart attack are correctly identified. Does imaging of coronary arteries and other subclinical evaluation, i.e. carotid IMT, provide better information on deciding what individuals need more aggressive therapy than traditional risk scores? [99].

The imaging of coronary arteries, i.e. measurement of coronary calcium, is not widely accepted as a standard preventive medicine practice to identify individuals at risk of clinical CHD events. An argument of many naysayers is that measurement of coronary calcium has not been proven in a clinical trial to reduce the incidence of CHD or CHD deaths and that the radiation dose might increase the risk of cancer and negate any benefits from the wide use of this technology. It has also been suggested that measurement of coronary calcium will lead to unnecessary further diagnostic and surgical procedures and therefore substantially increase health care costs $[100,101]$.

It is also suggested that individuals will have heart attacks with relatively little coronary atherosclerosis whether measured indirectly by coronary calcium, i.e. 0 coronary calcium score, or by the extent of coronary stenosis as measured by angiography or at postmortem examination. Such individuals are rare in the population. The pathogenesis of heart attacks among such individuals may be due to coronary artery spasm, rupture of an isolated coronary plaque or possibly due to unexpected stressors, such as tachycardia, vasovagal response, extensive bleeding. It is also possible that there is a small population which has only noncalcified atherosclerotic plaques and still has a significant atherosclerosis burden in spite of a low coronary calcium score. However, the number of such individuals must be very low given the extremely low risk of CHD, at least over 5-6 years, among individuals with 0 coronary calcium scores [102].

Newer diagnostic techniques using multiple-detector computed tomography (MDCT) [103, 104], especially with contrast agents can identify both noncalcified and calcified plaques. This has led to proposal that these new methods are superior than to just measuring coronary calcium as a screening technique. However, there is no evidence that MDCT, measurement of both calcified and noncalcified plaques, among normal asymptomatic individuals improved risk prediction above measurement of only coronary calcium. There is no consistent evidence that noncalcified plaques are associated with higher risk of clinical CHD than calcified plaques. It is likely that almost all individuals who have multiple noncalcified plaques have calcified plaques as well and will have high calcium scores.

Traditional risk factors that are part of risk assessment are strongly related to the development of atherosclerosis and to the extent of coronary calcium [28, 105]. The association is not $1: 1$ however. If there was a perfect $1: 1$ relationship between risk factors such as LDL-C and extent of atherosclerosis then measures of coronary atherosclerosis, i.e. coronary calcium, would be unnecessary. The reason why there is not a 1:1 relationship between risk factors and 
extent of coronary calcium are first, substantial withinindividual variation over time in risk factor levels. A single measurement of a risk factor is not the same as true mean, median for an individual over time, even in the short term. The incubation period is very long for the development of atherosclerosis and subsequent risk of clinical CHD and therefore the levels of risk factors measured early in life and the changes in these risk factors over time contribute to the progression of atherosclerosis. A lipid level measured several years before a coronary calcium study may miss the lifetime risk exposure. A recent long term 30-40 year follow up from a Chicago cohort documented a strong positive association between risk factor levels at younger ages and extent of coronary calcium 30-40 years later [2]. Similarly, genetic studies demonstrate substantial increased risk of both CHD and extent of atherosclerosis in individuals with elevated childhood blood LDL due to specific genetic polymorphisms [106].

Short term, 10-year, risk scores determined at time of coronary calcium measurement results in substantial misclassification of the extent of coronary atherosclerosis especially among women and younger age groups [107, 108]. For example, in a study involving 2, 447 nondiabetic asymptomatic women, mean age $55 \pm 10$ years, $90 \%$ of the women were classified as low risk, $10 \%$ as intermediate risk and none as being high risk, i.e. $>20 \%$ risk of clinical CHD in 10 years. Coronary calcium, however, was present in $33 \%$ of the women and $13 \%$ had coronary calcium $>100$ which is associated with a high risk of CHD. $20 \%$ had age- and gender-adjusted coronary calcium scores $>75^{\text {th }}$ percentile and $84 \%$ of these women were classified as low risk.

The Multi-Ethnic Study of Atherosclerosis (MESA) study reported that for coronary calcium measurement among both men and women, the risk of heart attack by level of coronary calcium was independent of the FRS, at least within the intermediate risk level of FRS, for the majority of the participants. They further identified the disconnect between recommendations for lipid lowering therapy based on ATP III guidelines and coronary calcium measurements at baseline. For example, among 663 participants with coronary calcium score $>400$, clearly at very high risk of clinical CHD, only $1 / 2$ met current ATP III criteria for lipid lowering therapy. On the other hand, among 3, 361 with 0 coronary calcium scores and at a very low risk for clinical CHD events, 674 (approximately 20\%) were candidates for lipid lowering therapy based on ATP III guidelines [109]. The amount of coronary calcium is a measure of atherosclerosis. It should not be primarily used as a method to reclassify individuals based on a Framingham or similar risk score. Atherosclerosis, not a risk score or lipid level, is the determinant of likelihood of clinical CHD.

Measurement of coronary calcium does not provide a good technique for determining progression of coronary atherosclerosis. There is little evidence at the present time that lipid lowering therapies modify the progression of coronary calcium scores [110-114]. Most of these studies evaluating lipid lowering have involved populations with high coronary calcium scores. It is possible that coronary calcium measurements may still be useful for evaluating progression from 0 or very low coronary calcium over time [115].
There is little evidence that measurement of coronary calcium results in substantial increase in further invasive diagnostic tests. Individuals with very high coronary calcium scores have an increased likelihood of further invasive diagnostic tests $[67,116]$. In populations with very low incidence and mortality due to $\mathrm{CHD}$, the prevalence of atherosclerosis will be low and therefore a much lower percentage of the population will be identified as having any coronary calcium or coronary occlusion. In such populations, the value of imaging to identify high risk individuals for preventive therapies and reduction of CHD may not be cost effective [117].

The radiation dose from coronary $\mathrm{CT}$ has been implicated as a reason for not recommending screening for coronary calcium or noncalcified d plaque. A Scientific Advisor from the American Heart Association noted that the effective dose for coronary calcium scan was $3 \mathrm{msv}$ to $9 \mathrm{msv}$ using a 64-slice coronary CT, with modifications [103]. They noted that it is extremely difficult to estimate risk, morbidity or mortality at these low radiation doses. Average background radiation in the United States is between 1-10 msv. They noted that the population lifetime risk of developing a malignancy is about $41 \%$ and dying of malignancy is about $21 \%$. Compared with the lifetime risk, coronary CT angiography with a $10 \mathrm{msv}$ dose increases the risk of cancer by $0.05 \%$. Arguably a trivial effect but one that could be important at the population level with many thousands of tests being performed [118-120]. A recent report from the Radiological Society of North America estimated that the average lifetime risk of developing radiation-induced cancer (mostly lung cancer) following a cardiac CT is $0.12 \%$ [121]. No study has actually measured the risk of developing either cancer in general or site-specific cancer following CT or similar procedures or at similar dose of radiation [122]. Such a study would require an extremely large sample size and is probably not feasible. Furthermore, another recent study documented that prospective gating of multidetector CT (MDCT) test would substantially reduce the exposure dose $[123,124]$. Widespread use of coronary CT will require continued careful monitoring of radiation exposure and efforts to minimize dose. There is little indication for frequent repeat coronary calcium studies [125].

Risk assessment either by scores such as the FRS or measurement of subclinical vascular disease such as coronary calcium scores will not reduce the incidence of $\mathrm{CHD}$ in and of themselves. Individuals identified for specific pharmacological or even nonpharmacological therapy must adhere to long term therapy with a reduction in the level of the risk factors. Poor adherence to therapies may be the single most important impediment to a major reduction in the incidence of CHD and CVD irrespective of the risk assessment method. The ability of various risk assessment methodologies to increase adherence to recommended therapies become an important component of the evaluation. For example, will individuals identified as having a higher coronary calcium score adhere to long term pharmacological therapies better than similar individuals identified as intermediate or high risk by an elevated FRS? [116, 126]. 
Recent studies have suggested improvement in adherence to therapies after CT scanning, especially for individuals with high coronary calcium $[97,116,125,126]$.

Measurement of carotid IMT and plaque by ultrasound is correlated with the extent of coronary atherosclerosis and coronary calcium, as well as with levels of traditional risk factors, (especially BP, lipoproteins, and the presence of diabetes) [127-129]. Intervention studies have generally shown that reduction of risk factors, such as BP or LDL-C or increased HDL-C, results in regression or slowing of progression of IMT $[130,131]$. Regression or slowing of progression of carotid IMT has been correlated with reduced incidence of CHD [132-133]. Recent studies have measured the type of plaque in the carotid artery using MRI or ultrasound and reported differential risk of both stroke and CHD by characteristics of plaque [134]. Carotid ultrasound or MRI has been proposed as a method of identifying "vulnerable plaques." [135, 136] MRI may also be a future method to measure extent of coronary artery disease [137, 138]. Carotid IMT has been proposed as an alternative to coronary calcium because of lower cost, no radiation exposure and better quantitative screening. There may be an important role of carotid IMT in evaluating younger individuals. Also at present it may be the only population measurement of progression or regression of disease in primary prevention, i.e. patients without prior CHD, CVD. The basic problem with the use of IMT is that it is a composite measure of both intima and media changes in the vessel and is therefore affected by vascular remodeling in response to atherosclerosis. In addition it remains very technician dependant for quality and reproducibility [139, 140].

Intravascular ultrasound (IVUS) is an invasive approach that has been used very successfully to measure changes in atherosclerosis within the coronary arteries in relationship to various interventions, including the effects of both HDL-C and LDL-C primarily in individuals with preexisting CVD [141-143]. IVUS has been used in a series of clinical trials to document the benefits of more aggressive therapies to modulate regression of atherosclerosis $[144,145]$. There is a good correlation between changes in plaque and reduction in the incidence of CHD. IVUS is an invasive technique limited usually to individuals who have clinical CHD and has provided the best evidence to date of effects of interventions to modify plaque progression [146].

\section{RISK FACTOR REDUCTION AND CHD INCIDENCE}

There are no clinical trials demonstrating that lowering the LDLC, ApoB, LDL-P among individuals who have high coronary calcium scores but intermediate or low FRS or other risk scores results in a reduction in clinical CHD events [147]. Invasive and noninvasive techniques, i.e. angiography, IVUS, carotid ultrasound, have documented that lipid lowering or other risk factor modification results in a decrease in the extent of atherosclerosis. Reduction in risk of CHD is noted across the entire level of LDL-C. This strongly suggests that lipid lowering among individuals with significant atherosclerosis, i.e. high coronary calcium score, will result in decreased risk of clinical CHD.

There is no clinical trial evidence that use of FRS or other risk scores results in a decreased incidence of or mortality due to clinical CHD. A "screening test" does not by itself reduce incidence of disease. The therapeutic decisions based on screening tests and how successful they are applied determine the benefit of a screening test. A proposal for a trial to determine whether measurement of coronary calcium reduces risk of CHD will be very expensive, over a long time period and will likely demonstrate that more at-risk individuals on statin therapy have a lower risk of CHD.

\section{PROPOSED RECOMMENDATIONS}

We believe that any risk assessment method should identify at least $80 \%$ of individuals likely to have a heart attack over 30-40 years. None of the current risk assessment methods except measurements of coronary calcium or abandoning risk assessment and treating practically everyone or greater than low long term risk, or the polypill approach, can reach this goal. There is relatively little difference between treating the $75 \%$ of the population over age 20 , i.e. 117 million, who have higher lifetime risk versus the polypill [66].

Psaty, et al., [148-151] have suggested that treating most adults except for very low risk was cheaper than coronary calcium screening. The costs of coronary calcium screening are determined by cost of test, including interpretation, and need for repeat screening over time. A possible design (Figs. 1, 2) shows that coronary calcium screening is probably equal or less costly than treating everyone over 40 or 50 years of age with lipid lowering therapy. The key cost variables are cost of $\mathrm{CT}$ screening; frequency of $\mathrm{CT}$ examination; costs of drug(s) and cost of physician visits. The advantage of coronary calcium screening is that higher at-risk individuals can be identified. The preventive therapies can be stratified by the extent of coronary calcium. There is a small percentage of older women with 0 coronary calcium who do not need lipid lowering drug therapy.

The proposed model suggests that repeat coronary calcium studies are probably unnecessary for most individuals once presence of coronary calcium is detected, at least $\geq 10$ Agatston units, because regression of coronary calcium scores is rare and progression is poorly correlated with "treatment effect, " i.e. lipid lowering. For individuals with 0 coronary calcium, repeat scan every 10 years is probably adequate given an average of conversion from 0 to any calcium of about $6 \% /$ year, at least for older men and women. Studies show that risk of CHD is very low for 0 coronary calcium, at least over the next 5-6 years.

The model assumes that: 1) very high risk individuals will be provided preventive pharmacological therapies without prior coronary calcium measures, including men and women over 40 years of age with type 1,2 diabetes, strong family history of premature CHD, very high ApoB, LDL-C levels and/or cigarette smokers. This model substantially reduces radiation exposure and costs of screening. We estimate a cost of $\$ 200$ per scan. For a cohort of 1000 women as shown in Fig. (1) there would be approximately 2,000 scans over 30 years at a cost of about $\$ 400,000$. For men (Fig. 2), from age 45-70+, there would also be about 2, 000 scans at accost of $\$ 400,000$. An increase in frequency of scans to every 5 years would not double cost because individuals with new coronary calcium would not need repeat scans. 


\section{Nondiabetic Women}

A.

Coronary calcium -Yes $33 \%$

330

Lipid lowering $<70$ or $<100 \mathrm{mg} \% \mathrm{LDL}$ or ApoB based on extent of coronary calcium

BP control - 130/80 mmHg Noncigarette smoking<smiles>C=[V]</smiles>

Reduction of $\mathrm{HbA}_{1}<6.5$ Recommend exercise program

B.

Coronary calcium - No $67 \%$

670

Repeat screen at age 65

C.

$50 \%$ Coronary calcium

Treat lipid lowering

330

$\wedge$
D.

$50 \%$ No coronary calcium

330

Repeat age 75 Treat as in A. if calcium positive (probably 50\%)

Fig. (1). Age 55 begin screening - women.

\section{Nondiabetic Men}

A.

Coronary Calcium - Yes

$50 \%$

500

Lipid lowering -

$<70$ or 100 based on extent of coronary calcium<smiles>C[AlH]</smiles>

BP control - 130/80 mmHg Noncigarette smoking

Reduction of $\mathrm{HbA}_{1}<6.5$ Recommend exercise program Possible $80 \mathrm{mg}$ aspirin
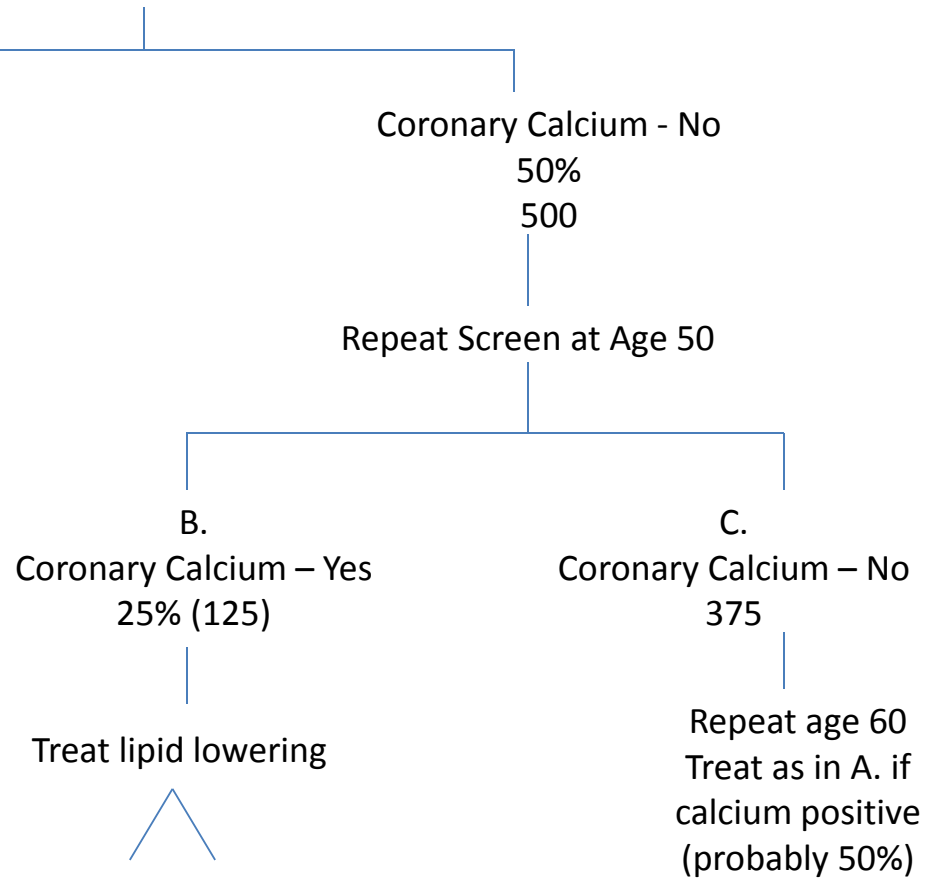

As in A.
Repeat age 70, as above

Fig. (2). Age 45 begin screening - men. 
The cost of lipid lowering therapy is estimated at about $\$ 80-100 /$ per year (generic). For women (Fig. 1), 330 women age 55-64 would be treated, 670 age $65-74$ and 850 age $75-$ 84 excluding deaths and dropouts, at a total cost of $\$ 1,482$, 100. If all women age $55+$ were put on lipid lowering drug therapy the cost would be $\$ 2,400,000$ over 30 years. Therefore, for women the costs of screening and selective lipid lowering drug therapy is a little lower than treating all women at age 55. Similarly, for men cost of drug therapy age 45-80+ would be about $\$ 2,300,000$. The cost of lipid lowering therapy may be too low because a percentage of individuals will require more potent lipid lowering drugs that are not "generic." However, the cost would likely be similar for any method of risk assessment. The costs of other drug therapy to lower BP, etc. would probably not be different by method of risk categorization since everybody with $\mathrm{BP} \geq 130$ to $140 \mathrm{mmHg}$ based on current guidelines would be treated. Aspirin is very inexpensive and would not contribute much to overall costs. There is still controversy about aspirin's risks-benefits in primary prevention. Important unanswered questions are whether individuals with impaired fasting glucose or glycohemoglobin $>6.0-6.5$ but not diabetic should be placed on glucophage and/or nonpharmacological therapy or other glucose lowering drugs and how to treat individuals with low HDL-C and elevated triglycerides. Clinical trials using HDL-C as a target of therapy have been disappointing but newer, more potent drugs may change the risk-benefit ratio [152].

We estimate that the 10-year incidence of CHD was 5\% among women age $55-64,10 \%$ age $65-74$ and $20 \%$ age $75-$ 84 , i.e. 315 events between age 55-84 per 1,000 women. Ninety percent will occur among women with some coronary calcium ( $\mathrm{n}=283$ ). If preventive therapy is $80 \%$ successful, then the reduction in risk of CHD event will be 225 or $68 \%$ and if $80 \%$ occur among women with coronary calcium $(\mathrm{n}=252)$ and $80 \%$ prevented 201 , or about $2 / 3$ of CHD events can be prevented at relatively low cost. The estimates are similar for men (see Appendix Table). Assume 550 CHD events age $45-84,90 \%$ had coronary calcium, $80 \%$ effective in reducing CHD or 396 events.

The major limiting variable will be the need to maximize long term adherence. A simplified screening program and preventive therapy with much greater emphasis on long term adherence will greatly improve a preventive program. The current approaches of complex risk assessment and tailored therapies, costly follow up physicians visits likely results in poor adherence to preventive therapies by focusing on diagnostic testing and complex guidelines and more expensive drug therapy.

\section{DISCUSSION}

CHD is preventable. We need better strategies to maximize the percentage of at-risk populations receiving optimal preventive therapy(ies), both pharmacological and nonpharmacological.

The proposed preventive strategy has 3 pieces. First, for children and young adults there should be a much greater efforts to prevent cigarette smoking, the rise in risk factors, BP, ApoB lipoproteins, blood glucose, weight, and increase physical activity. If we do not modify risk factors in young adults now, then we are doomed to a continued endemic of
CVD [153-155]. This should remain a very high priority. Second, for very high risk young adults $<45$ for men, 55 for women, as previously defined, apply pharmacological or nonpharmacological individualized primary prevention of elevated risk factors. Third, at age 45 for men and 55 for women, begin CT screening for coronary calcium. Everyone with coronary calcium either $\geq 0$ or $>10$ requires pharmacological-based risk factor reduction to slow or prevent progression of atherosclerosis and incident clinical CHD. Repeat coronary calcium at periodic intervals, approximately every 10 years only for those with 0 or $<10$ coronary calcium scores to age $75-80$. The intensity of lipid lowering therapy, BP reduction, other therapies, would be individualized by physicians and based on initial coronary calcium score and level of risk factor(s).

Fitness as measured by maximal exercise testing could provide an important adjustment to risk stratification based on imaging. How such information would be used needs further evaluation [156]. A clinical trial to evaluate the role of "fitness," as opposed to ischemic changes, as measured by exercise testing in combination with coronary calcium measurements and aggressive pharmacological and non therapies, such as exercise, could provide important new information. A basic problem could be implementation of maximal exercise testing, standardization, costs and willingness of individuals to complete these tests. Similarly, any new pharmacological therapies will require clinical trials. The Psaty recommendation to place practically all adults on lipid lowering therapy could be a viable alternative in populations that lack cost-effective imaging facilities.

New research should focus on better risk markers that would enhance short term prediction of a heart attack, including thrombogenesis, unfavorable changes in plaque morphology, and platelet function. We are still unable to predict very short term risk of a heart attack. If, for example, could we monitor a blood marker of change in platelet function, risk of thrombosis, depressed fibrinolysis, or inflammation, in a plaque that is likely to rupture and could do so in a cost effective manner, it would be advantageous. Sadly, to date we have not been very successful $[157,158]$.

There is a need for better nonpharmacological and pharmacological therapies, i.e. exercise, omega-3 fatty acids, vitamin $\mathrm{D}$, antiplatelet aggregating agents, clotting inhibitors, that can be demonstrated to reduce risk of thrombosis, rupture, fissure in plaque, etc., precipitants of heart attack, that are both safe and efficacious.

This approach does not preclude the development and replacement of CT for measurement of coronary calcium by new imaging technology, especially noninvasive, safe, low cost and low radiation approaches that can monitor effects of therapies on the extent of atherosclerosis and risk of CHD over time in primary prevention. Measurement of coronary calcium, as noted, does not provide a good approach for evaluation of effects of therapies and, therefore, once an individual has coronary calcium at least above 10 Agatston units, repeat calcium measurements, except in research, are of limited value. IVUS at present is the best approach for monitoring effects of therapy or progression of coronary atherosclerosis but is too invasive for application to the general population. MRI may be an approach for the future. 
Standardization of new imaging techniques and readings should be a high priority.

We need improved systems approaches to delivering long term, lower cost preventive therapies for large numbers of asymptomatic individuals. Delivery of preventive services in physicians' offices will not be cost effective and will likely result in high rates of nonadherence to therapy and loss to follow up. Physicians are responsible for preventive therapies but require substantial ancillary support to maintain adherence and follow up for asymptomatic individuals.

Our prevention approaches must reach the lower socioeconomic and higher risk populations and decrease the substantial disparities in CVD. A simplified, lower cost approach is much more likely to be successful.

\section{CONCLUSION}

CHD is preventable. Incidence and death rates due to CHD and vascular disease are too high in many countries and within countries, there remains substantial disparity of CHD rates. A successful prevention program must focus on prevention of atherosclerosis beginning in childhood by lowering the multiple risk factors. Hopefully in the future, better genetic approaches will improve our ability to identify "susceptible" individuals and improve selection of specific drug therapies. That said, atherosclerosis is very prevalent in the population and it is extremely doubtful that we will identify a genetic footprint for "susceptibles" versus "nonsusceptibles."

The proposed preventive approach using imaging and simple, low cost and safe preventive therapies can substantially reduce CHD incidence and also stroke, greatly reduce costs of treatment of $\mathrm{CHD}$ and reduce population radiation exposure by decreasing incidence of CHD [159]. Finally, any screening program or risk assessment alone will have little effect on reducing CHD morbidity, mortality and disparities within and among populations. The key is correctly using the information to maximize prevention of atherosclerosis, thrombosis and clinical disease.

\section{ACKNOWLEDGEMENT}

None declared.

\section{CONFLICT OF INTEREST}

None declared.

\section{REFERENCES}

[1] Wilson PW, D'Agostino RB, Levy D, et al. Prediction of coronary heart disease using risk factor categories. Circulation 1998; 97: 183747.

[2] Daviglus ML, Liu K, Lloyd-Jones DM, et al. Low cardiovascular risk profile in younger age and quantity of coronary artery calcium in older age: preliminary results from the Chicago Healthy Aging Study (CHAS) [abstract 1185]. Circulation 2009; 120: S462.

[3] Lloyd-Jones DM, Leip EP, Larson MG, et al. Prediction of lifetime risk for cardiovascular disease by risk factor burden at 50 years of age. Circulation 2006; 113: 791-8.

[4] Cooney MT, Dudina AL, Graham IM. Value and limitations of existing scores for the assessment of cardiovascular risk. A review for clinicians. J Am Coll Cardiol 2009; 54: 1209-27.

[5] Beswick A, Brindle P. Risk scoring in the assessment of cardiovascular risk. Curr Opin Lipidol 2006; 17: 375-86.

[6] Arsenault BJ, Rana JS, Stroes ES, et al. Beyond low-density lipoprotein cholesterol. Respective contributions of non-high-density lipoprotein cholesterol levels, triglycerides, and the total cholesterol/high-density lipoprotein cholesterol ratio to coronary heart disease risk in apparently healthy men and women. J Am Coll Cardiol 2009; 55: 35-41.

[7] Mills EJ, Rachlis $\mathrm{B}$, Wu $\mathrm{P}$, et al. Primary prevention of cardiovascular mortality and events with statin treatments: a network meta-analysis involving more than 65, 000 patients. J Am Coll Cardiol 2008; 52: 1769-81.

[8] Stamler J, Neaton JD, Garside DB, Daviglus ML. In: Marmot M, Elliot P, Eds. Coronary heart disease epidemiology. From aetiology to public health, $2^{\text {nd }}$ ed. Oxford, UK: Oxford University Press 2004; pp. 32-70.

[9] Greenland P, Gidding SS, Tracy RP. Commentary: lifelong prevention of atherosclerosis: the critical importance of major risk factor exposures. Intl J Epidemiol 2002; 30: 1129-34

[10] Lloyd-Jones D, Adams R, Carnethon M, et al. Heart disease and stroke statistics-2009 update. A report from the American Heart Association Statistics Committee and Stroke Statistics Subcommittee. Circulation 2009; 119: e21-e181.

[11] Sekikawa A, Ueshima H, Kadowaki T, et al. Less subclinical atherosclerosis in Japanese men in Japan than in White men in the United States in the post-World War II birth cohort. Am J Epidemiol 2007; 165: 617-24.

[12] Santos RD, Nasir K, Rumberger JA, et al. Difference in atherosclerosis burden in different nations and continents assessed by coronary artery calcium. Atherosclerosis 2006; 187: 378-84.

[13] Abbott $\mathrm{RD}$, Ueshima $\mathrm{H}$, Rodriguez $\mathrm{BL}$, et al. Coronary artery calcification in Japanese men in Japan and Hawaii. Am J Epidemiol 2007; 66: 1280-7.

[14] Chen Z, Peto R, Collins R, et al. Serum cholesterol concentration and coronary heart disease in population with low cholesterol concentrations. BMJ 1991; 303: 276-82.

[15] Emerging Risk Factors Collaboration. Di Angelantonio E, Sarwar N, Kaptoge S, et al. Major lipids, apolipoproteins, and risk of vascular disease. JAMA 2009; 302: 1993-2000.

[16] McGill HC Jr, McMahan CA, Gidding SS. Preventing heart disease in the $21^{\text {st }}$ century. Implications of the Pathobiological Determinants of Atherosclerosis in Youth (PDAY) Study. Circulation 2008; 117: 1216-27.

[17] Ford ES, Giles WH, Mokdad AH. The distribution of 10-year risk for coronary heart disease among U.S. adults. J Am Coll Cardiol 2004; 43: 1791-6.

[18] Ajani Ua, Ford ES. Has the risk for coronary heart disease changed among U.S. adults? J Am Coll Cardiol 2006; 48: 1177-82.

[19] Lopez-Jimenez F, Batsis JA, Roger VL, et al. Trends in 10-year predicted risk of cardiovascular disease in the United States, 1976 to 2004. Circ Cardiovasc Qual Outcomes 2009; 2: 443-50.

[20] McGill HC Jr, McMahan CA, Zieske AW, et al. Associations of coronary heart disease risk factors with the intermediate lesion of atherosclerosis in youth. Arterioscler Thromb Vasc Biol 2000; 20: 1998-2004.

[21] Tejada C, Strong JP, Montenegro MR, Restrepo C, Solberg LA. In: McGill HC Jr, Ed. The geographic pathology of atherosclerosis. Baltimore, MD: Williams \& Wilkins Company. 1968; pp. 509-26.

[22] Newman AB, Naydeck BL, Ives DG, et al. Coronary artery calcium, carotid artery wall thickness, and cardiovascular disease outcomes in adults 70 to 99 years old. Am J Cardiol 2008; 101: 186-92.

[23] Kuller LH, Arnold AM, Psaty BM, et al. 10-year follow-up of subclinical cardiovascular disease and risk of coronary heart disease in the Cardiovascular Health Study. Arch Intern Med 2006; 166: 718.

[24] Ankle Brachial Index Collaboration. Ankle brachial index combined with Framingham risk score to predict cardiovascular events and mortality. A meta-analysis. JAMA 2008; 300: 197-208.

[25] Kuller LH. Cardiovascular disease is preventable among women. Expert Rev Cardiovase Ther 2010; 8: 175-87.

[26] Fuster V, Bansilal S. Promoting cardiovascular and cerebrovascular health. Stroke 2010; 41: 1079-83.

[27] Fuster V, Moreno PR, Fayad ZA, Corti R, Badimon JJ. Atherothrombosis and high-risk plaque: Part I: evolving concepts. J Am Coll Cardiol 2005; 46: 937-54.

[28] Kuller LH, Matthews KA, Edmundowicz D, Chang Y. Incident coronary artery calcium among postmenopausal women. Atherosclerosis 2008; 200: 273-85.

[29] Stamler J, Stamler R, Neaton JD, et al. Low risk-factor profile and long-term cardiovascular and noncardiovascular mortality and life expectancy. JAMA 1999; 282: 2012-8. 
[30] Marma AK, Berry JD, Ning H, Persell SD, Lloyd-Jones DM. Distribution of 10-year risk and lifetime predicted risks for cardiovascular in US adults: findings from the National Health and Nutrition Examination Survey 2003 to 2006. Circ Cardiovasc Qual Outcomes 2010; 3: 8-14

[31] Wilson PWF, D'Agostino RB, Levy D, et al. Prediction of coronary heart disease using risk factor categories. Circulation 1998; 97: 183747

[32] Stamler J, Daviglus ML, Garside DB, et al. Relationship of baseline serum cholesterol levels in 3 large cohorts of younger men to longterm coronary, cardiovascular, and all-cause mortality and to longevity. JAMA 2000; 284: 311-8.

[33] Min JK, Lin FY, Gidseg DS, et al. Determinants of coronary calcium conversion among patients with a normal coronary calcium scan. What is the "warranty period" for remaining normal? J Am Coll Cardiol 2010; 55: 1110-7.

[34] Kuller LH. Prevention of coronary heart disease and the National Cholesterol Education Program. Circulation 2006; 113: 598-600.

[35] Ardehali R, Nasir K, Kolandaivelu A, Budoff MJ, Blumenthal RS. Screening patients for subclinical atherosclerosis with non-contrast cardiac CT. Atherosclerosis 2007; 192: 235-42.

[36] Eagle KA, Ginsburg GS, Musunuru K, et al. Identifying patients at high risk of a cardiovascular event in the near future: current status and future directions: report of a National heart, Lung, and Blood Institute working group. Circulation 2010; 121: 1447-54.

[37] Missel E, Mintz GS, Carlier SG, et al. In vivo virtual histology intravascular ultrasound correlates of risk factors for sudden coronary death in men: results from the prospective, multi-centre virtual histology intravascular ultrasound registry. Eur Heart J 2008; 29: 2141-47.

[38] Gurfinkel E, Vigliano C, Janavel JV, et al. Presence of vulnerable coronary plaques in middle-aged individuals who suffered a brain death. Eur Heart J 2009; 30: 2845-53.

[39] Bharucha NE, Raven RH, Schoenberg BS. In: Anderson DW, Ed. Neuroepidemiology: a tribute to Bruce Schoenberg. Boca Raton, FL: CRC Press, Incidence. 1990; pp. 311-31.

[40] Sheps MC. Shall we count the living or the dead? N Engl J Med 1958; 259: 1210-4.

[41] Unal B, Critchley JA, Capewell S. Explaining the decline in coronary heart disease mortality in England and Wales between 1981 and 2000. Circulation 2004; 109: 1101-7.

[42] Palmieri L, Bennett K, Giampaoli S, Capewell S. Explaining the decrease in coronary heart disease mortality in Italy between 1980 and 2000. Am J Public Health 2010; 100: 684-92.

[43] Roger VL, Weston SA, Gerber Y, et al. Trends in incidence, severity, and outcome of hospitalized myocardial infarction. Circulation 2010; 121: 863-9.

[44] Chen J, Normand S-LT, Wang Y, et al. Recent declines in hospitalizations for acute myocardial infarction for Medicare fee-forservice beneficiaries. Progress and continuing challenges. Circulation 2010; $121: 1322-8$

[45] Kuller LH. Clinical implications of the BARI 2D and COURAGE trials of coronary artery disease. Coron Artery Dis 2010; 21: 391-6.

[46] Roehrig C, Miller G, Lake C, Bryant J. National health spending by medical condition, 1996-2005. Health Aff 2009; 28: w358-67.

[47] Capewell S, Ford ES, Croft JB, et al. Cardiovascular risk factor tends and potential for reducing coronary heart disease mortality in the United States of America. Bull World Health Organ 2010; 88: 12030.

[48] Ford ES, Li C, Zhao G, Mokdad AH. Concentrations of low-density lipoprotein cholesterol and total cholesterol among children and adolescents in the United States. Circulation 2009; 119: 1108-15.

[49] Berenson GS, Srinivasan SR. Cardiovascular risk in young persons: secondary or primordial prevention? Ann Intern Med 2010; 153: 2013.

[50] Greenland P, Gidding SS, Tracy RP. Commentary: Lifelong prevention of atherosclerosis: the critical importance of major risk factor exposures. Int J Epidemiol 2002; 30: 1129-34.

[51] Berry JD, Liu K, Folsom AR, et al. Prevalence and progression of subclinical atherosclerosis in younger adults with low short-term but high lifetime estimated risk for cardiovascular disease. The Coronary Artery Risk Development in Young Adults Study and Multi-Ethnic Study of Atherosclerosis. Circulation 2009; 119: 382-9.

[52] Grundy SM, Cleeman JI, Merz CN, et al. Implications of recent clinical trials for the National Cholesterol Education Program Adult Treatment Panel III guidelines. Circulation 2004; 110: 227-39.
[53] Lloyd-Jones DM, Leip EP, Larson MG, et al. Prediction of lifetime risk for cardiovascular disease by risk factor burden at 50 years of age. Circulation 2006; 113: 791-8.

[54] Berger JS, Jordan CO, Lloyd-Jones D, Blumenthal RS. Screening for cardiovascular risk in asymptomatic patients. J Am Coll Cardiol 2010; 55: 1169-77.

[55] Barringer TA. Carotid IMT in clinical practice. The Lipid Spin 2009; 7: 4-8, 31 .

[56] Folsom AR, Chambless LE, Ballantyne CM, et al. An assessment of incremental coronary risk prediction using C-reactive protein and other novel risk markers: the Atherosclerosis Risk In Communities study. Arch Intern Med 2006; 166: 1368-73.

[57] Kim HC, Greenland P, Rossouw JE, et al. Multimarker prediction of coronary heart disease risk: the Women's Health Initiative. J Am Coll Cardiol 2010; 55: 2080-91.

[58] Madjid M, Ali M, Willerson JT. Lipoprotein-associated phospholipase $A_{2}$ as a novel risk marker for cardiovascular disease. Tex Heart Inst J 2010; 37: 25-39.

[59] Danesh J, Wheeler JG, Hirschfield GM, et al. C-reactive protein and other circulating markers of inflammation in the prediction of coronary heart disease. N Engl J Med 2004; 350: 1387-97.

[60] Gallacher J, Bayer A, Lowe G, et al. Is sticky blood bad for the brain? Hemostatic and inflammatory systems and dementia in the Caerphilly Prospective Study. Arterioscler Thromb Vasc Biol 2010; 30: 599-604.

[61] Wald NJ, Law MR. A strategy to reduce cardiovascular disease by more than $80 \%$. BMJ 2003; 26: 1419-24.

[62] Leupker RV. In: Marmot M, Elliott P, Eds. Coronary heart disease epidemiology. From aetiology to public health, $2^{\text {nd }}$ ed. Oxford, UK: Oxford University Press 2004; pp. 73-82.

[63] Daviglus ML, Lloyd-Jones DM, Pirzada A. Preventing cardiovascular disease in the $21^{\text {st }}$ century. Therapeutic and preventive implications of current evidence. Am J Cadiovasc Drugs 2006; 6: 87101.

[64] O'Keefe JH Jr, Cordain L, Harris WH, Moe RM, Vogel R. Optimal low-density lipoprotein is 50 to $70 \mathrm{mg} / \mathrm{dl}$. Low is better and physiologically normal. J Am Coll Cardiol 2004; 43: 2142-6.

[65] Law MR, Wald NJ, Morris JK, Jordan RE. Value of low dose combination treatment with blood pressure lowering drugs: analysis of 354 randomised trials. BMJ 2003; 326: 1427-34.

[66] Sniderman A. Targets for LDL-lowering therapy. Curr Opin Lipidol 2009; 20: 282-7.

[67] Baker LC, Atlas SW, Afendulis CC. Expanded use of imaging technology and the challenge of measuring value. Health Aff 2008; 27: $1467-78$.

[68] Krishnan GM, Thompson PD. The effects of statins on skeletal muscle strength and exercise performance. Curr Opin Lipidol 2010; 21:324-8.

[69] Pletcher MJ, Lazar L, Bibbins-Domingo K, et al. Comparing impact and cost-effectiveness of primary prevention strategies for lipidlowering. Ann Intern Med 2009; 150: 243-54.

[70] Tindle HA, Omalu B, Courcoulas A, et al. Risk of suicide after long term follow-up from bariatric surgery. Am J Med 2010; 123: 103642.

[71] Chobanian AV, Bakris GL, Black HR, National Heart, Lung, and Blood Institute Joint National Committee on Prevention, Detection, Evaluation, and Treatment of High Blood Pressure; National High Blood Pressure Education Program Coordinating Committee. The Seventh Report of the Joint National Committee on Prevention, Detection, Evaluation, and Treatment of High Blood Pressure: the JNC 7 report. JAMA 2003; 289: 2560-72.

[72] Kahn R, Robertson RM, Smith R, Eddy D. The impact of prevention on reducing the burden of cardiovascular disease. Circulation 2008; 1 18: 576-85.

[73] Laza, LD, Pletcher MJ, Coxson PG, Bibbins-Domingo K, Goldman L. Cost-effectiveness of statin therapy for primary prevention in a low-cost statin era. Circulation 2011; 124: 146-53.

[74] Marelli C, Gunnarsson C, Ross S, et al. Statins and risk of cancer. A retrospective cohort analysis of 45, 857 matched pairs from an electronic medical records database of 11 million adult Americans. J Am Coll Cardiol 2011; 58: 530-7.

[75] Egan A, Colman E. Weighing the benefits of high-dose simvastatin against the risk of myopathy. N Engl J Med 2011;365: 285-7.

[76] Perkins NJ, Schisterman EF. The inconsistency of "optimal" cutpoints using two ROC based criteria. Am J Epidemiol 2006; 163: 670-5. 
[77] Pencina MJ, D’Agostino RB Sr, D’Agostino RB Jr, Vasan RS. Evaluating the added predictive ability of a new marker: From area under the ROC curve to reclassification and beyond. Statist Med 2008; 27: 157-72.

[78] Berry JD, Lloyd-Jones DM, Garside DB, Greenland P. Framingham risk score and prediction of coronary heart disease death in young men. Am Heart J 2007; 154: 80-6.

[79] Marma AK, Berry JD, Ning H, et al. Distribution of 10-year risk and lifetime predicted risks for cardiovascular disease in US adults: findings from the National Health and Nutrition Examination Survey 2003 to 2006. Circ Cardiovasc Qual Outcomes 2010, 3:8-14.

[80] Sheridan SL, Viera AJ, Krantz MJ, et al. for the Cardiovascular Health Intervention Research and Translation Network Work Group on Global Coronary Heart Disease Risk. The effect of giving global coronary risk information to adults: a systematic review. Arch Intern Med 2010; 170: 230-9.

[81] Muller-Riemenschneider F, Holmberg C, Rieckmann N, et al. Barriers to routine risk-score use for healthy primary care patients. Survey and qualitative study. Arch Intern Med 2010; 170: 719-24.

[82] Ferket BS, Colkesen EB, Visser JJ, et al. Systematic review of guidelines on cardiovascular risk assessment. Which recommendations should clinicians follow for a cardiovascular health check? Arch Intern Med 2010; 170: 27-40.

[83] Smith SC Jr. Screening for high-risk cardiovascular disease. A challenge for guidelines. Arch Intern Med 2010; 170: 40-2.

[84] Law MR, Wald NJ, Morris JK. The performance of blood pressure and other cardiovascular risk factors as screening tests for ischaemic heart disease and stroke. J Med Screen 2004; 11: 3-7.

[85] D'Agostino RB Sr, Vasan RS, Pencina MJ, et al. General cardiovascular risk profile for use in primary care: The Framingham Heart Study. Circulation 2008; 117: 743-53.

[86] Cooney MT, Dudina A, D’Agostino R, Graham IM. Cardiovascular risk-estimation systems in primary prevention. Do they differ? Do they make a difference? Can we see the future? Circulation 2010; 122: 300-10.

[87] Persell SD, Zei C, Cameron KA, Zielinski M, Lloyd-Jones DM. Potential use of 10-year and lifetime coronary risk information for preventive cardiology prescribing decisions. A primary care physician survey. Arch Intern Med 2010; 170: 470-7.

[88] Humphries JD, Kuller LH, Ross RS, et al. Natural history of ischemic heart disease in relation to arteriographic findings: A twelve year study of 224 patients. Circulation 1974; 49: 489-97.

[89] Criqui MH, Langer RD, Fronek A, et al. Mortality over a period of 10 years in patients with peripheral arterial disease. N Engl J Med 1992; 326: 381-6.

[90] Newman AB, Siscovick DS, Manolio TA, et al. The ankle-arm index as a marker of atherosclerosis in the Cardiovascular Health Study. Circulation 1993; 88: 837-45.

[91] Heiss G, Sharrett AR, Barnes R, et al. Carotid atherosclerosis measured by b-mode ultrasound in populations: associations with cardiovascular risk factors in the ARIC Study. Am J Epidemiol 1991; 134: 250-6.

[92] Kuller LH, Borhani N, Furberg C, et al. Prevalence of subclinical atherosclerosis and cardiovascular disease and association with risk factors in the Cardiovascular Health Study. Am J Epidemiol 1994; 139: 1164-79.

[93] Rennenberg RJMW, Kessels AGH, Schurgers LJ, et al. Vascular calcifications as a marker of increased cardiovascular risk: A metaanalysis. Vasc Health Risk Manag 2009; 5: 185-97.

[94] Alexopoulos N, Raggi P. Calcification in atherosclerosis. Nat Rev Cardiol 2009; 6: 681-8.

[95] Shaw LJ, Raggi P, Schisterman E, et al. Prognostic value of cardiac risk factors and coronary artery calcium screening for all-cause mortality. Radiology 2003; 228: 826-33.

[96] Raggi P, Gongora MC, Gopal A, et al. Coronary artery calcium to predict all-cause mortality in elderly men and women. J Am Coll Cardiol 2008; 52: 17-23.

[97] Rozanski A, Gransar H, Shaw LJ, et al. Impact of coronary artery calcium scanning on coronary risk factors and downstream testing. The EISNER (Early Identification of Subclinical Atherosclerosis by noninvasive Imaging Research) prospective randomized trial. J Am Coll Cardiol 2011; 57: 1622-32.

[98] Greenland P, Bonow RO. How low-risk is a coronary calcium score of zero? The importance of conditional probability. Circulation 2008; 117: $1627-9$
[99] Duivenvoorden R, Nederveen AJ, de Groot E, Kastelein JJP. Atherosclerosis imaging as a benchmark in the development of novel cardiovascular drugs. Curr Opin Lipidol 200; 18: 613-21.

[100] Lauer MS. Discarding logic. 2008 Ancel Keys memorial lecture Circulation 2009;119: 1533-7.

[101] Douglas PS, Taylor A, Bild D, et al. Outcomes research in cardiovascular imaging. Report of a workshop sponsored by the National Heart, Lung, and Blood Institute. JACC: Cardiovasc Imaging 2009; 2: 897-907.

[102] Min JK, Hachamovitch R, Rozanski A, et al. Clinical benefits noninvasive testing: coronary computed tomography angiography as a test case. JACC: Cardiovasc Imaging 2010; 3: 305-14.

[103] Rivera JJ, Nasir K, Cox PR, et al. Association of traditional cardiovascular risk factors with coronary plaque sub-types assessed by 64-slice computed tomography angiography in a large cohort of asymptomatic subjects. Atherosclerosis 2009; 206: 451-7.

[104] van Werkhoven JM, Schuijf JD, Gaemperli O, et al. Incremental prognostic value of multi-slice computed tomography coronary angiography over coronary artery calcium scoring in patients with suspected coronary artery disease. Eur Heart J 2009; 30: 2622-9.

[105] Bild DE, Detrano R, Peterson D, et al. Ethnic differences in coronary calcification: the Multi-Ethnic Study of Atherosclerosis (MESA). Circulation 2005; 111: 1313-20.

[106] Kathiersan S, Melander O, Anevski D, et al. Polymorphisms associated with cholesterol and risk of cardiovascular events. N Engl J Med 2008; 358: 1240-9.

[107] Detrano R, Guerci AD, Carr JJ, et al. Coronary calcium as a predictor of coronary events in four racial or ethnic groups. N Engl J Med 2008; 358: 1336-45.

[108] Michos ED, Nasir K, Braunstein JB, et al. Framingham risk equation underestimates subclinical atherosclerosis risk in asymptomatic women. Atherosclerosis 2006; 84: 201-6.

[109] Goff DC Jr, Bertoni AG, Kramer H, et al. Dyslipidemia prevalence, treatment, and control in the Multi-Ethnic Study of Atherosclerosis (MESA): gender, ethnicity, and coronary artery calcium. Circulation 2006; 113: 647-56.

[110] Schmermund A, Achenbach S, Budde T, et al. Effect of intensive versus standard lipid-lowering treatment with atorvastatin on the progression of calcified coronary atherosclerosis over 12 months. A multicenter, randomized, double-blind trial. Circulation 2006; 113 : 427-37.

[111] Arad Y, Spadaro LA, Roth M, et al. Treatment of asymptomatic adults with elevated coronary calcium scores with atorvastatin, vitamin $\mathrm{C}$, and vitamin E. The St. Francis Heart Study randomized clinical trial. J Am Coll Cardil 2005; 46: 166-72.

[112] Raggi P, Davidson M, Callister TQ, et al. Aggressive versus moderate lipid-lowering therapy in hypercholesterolemic postmenopausal women: beyond endorsed lipid lowering with EBT scanning (BELLES). Circulation 2005; 112: 563-71.

[113] Hecht HS. A zero coronary artery calcium score. Priceless. J Am Coll Cardiol 2010; 55: 1118-20.

[114] McCullough PA, Chinnaiyan KM. Annual progression of coronary calcification in trials of preventive therapies. Arch Intern Med 2009; 169: 2064-70.

[115] O'Malley PG. A double take on serial measurement of coronary artery calcification. Arch Intern Med 2009; 169: 2051-2.

[116] Kalia NK, Miller LG, Nasir K, Blumenthal RS, Agrawal N, Budoff MJ. Visualizing coronary calcium is associated with improvements in adherence to statin therapy. Atherosclerosis 2006; 185: 394-9.

[117] McEvoy JW, Blaha MJ, Nasir K, et al. Impact of coronary computed tomographic angiography results on patient and physician behavior in a low-risk population. Arch Intern Med 2011; 171: 1260-8.

[118] Laskey WK, Feinendegen LE, Neumann RD, Dilsizian V. Low-level ionizing radiation from noninvasive cardiac imaging: can we extrapolate estimated risks from epidemiologic data to the clinical setting? J Am Coll Cardiol Img 2010; 3: 517-24.

[119] Brenner DJ, Doll R, Goodhead DT, et al. Cancer risks attributable to low doses of ionizing radiation: Assessing what we really know. Proc Natl Acad Sci USA 2003; 100: 13761-6.

[120] Lauer M. Elements of danger-The case of medical imaging. N Engl J Med 2009; 361: 841-3.

[121] Mitka M. Cardiac CT cancer risks less than feared? JAMA 2009; 301: 367 .

[122] Bhatti P, Yong LC, Doody MM, et al. Diagnostic X-ray examinations and increased chromosome translocations: evidence from three studies (Abstract \#470). Am J Epidemiol 2010; 171: S1-157. 
[123] Kim KP, Einstein AJ, de Gonzalez AB. Coronary artery calcification screening. Estimated radiation dose and cancer risk. Arch Intern Med 2009; 169: 1188-94.

[124] Raff GL, Chinnaiyan KM, Share DA, et al. Radiation dose from cardiac computed tomography before and after implementation of radiation dose reduction techniques. JAMA 2009; 301: 2340-8.

[125] O’Malley PG, Feuerstein IM, Taylor AJ. Impact of electron beam tomography, with or without case management, on motivation, behavioral change and cardiovascular risk profile. A randomized controlled trial. JAMA 203; 289: 2215-23.

[126] Wong ND, Detrano RC, Diamond G, et al. Does coronary artery screening by electron beam computed tomography motivate health lifestyle behaviors? Am J Cardiol 1996; 78: 1220-3.

[127] Polak JF, Pencina MJ, Pencina KM, et al. Carotid-wall intima-media thickness and cardiovascular events. N Engl J Med 2011; 365: 21321.

[128] Chambless LE, Heiss G, Folsom AR, et al. Association of coronary heart disease incidence with carotid arterial wall thickness and major risk factors: the Atherosclerosis Risk in Communities (ARIC) Study, 1987-1993. Am J Epidemiol 1997; 146: 483-94.

[129] O'Leary DH, Polak JF, Kronmal RA, et al. Carotid-artery intima and media thickness as a risk factor for myocardial infarction and stroke in older adults. N Engl J Med 1999; 340: 14-22.

[130] Wang JG, Staessen JA, Li Y, et al. Carotid intima-media thickness and antihypertensive treatment. A meta-analysis of randomized controlled trials. Stroke 2006; 37: 1933-40.

[131] McCullough PA, Lepor NE. Lipids, biomarkers, and noninvasive imaging of atherosclerotic disease activity in clinical trials. Rev Cardiovasc Med 2008; 9: 142-9.

[132] Crouse JR III, Raichlen JS, Riley WA, et al. Effect of rosuvastatin on progression of carotid intima-media thickness in low-risk individuals with subclinical atherosclerosis: the METEOR trial. JAMA 2007; 297: 1344-53.

[133] Villines TC, Stanek EJ, Devine PJ, et al. The ARBITER 6-HALTS Trial (Arterial Biology for the Investigation of the Treatment Effects of Reducing Cholesterol 6-HDL and LDL Treatment Strategies in Atherosclerosis): final results and the impact of medication adherence, dose, and treatment duration. J Am Coll Cardiol 2010; 55: 2721-6.

[134] Silvera SS, Aidi HE, Rudd JH, et al. Multimodality imaging of atherosclerotic plaque activity and composition using FDG-PET/CT and MRI in carotid and femoral arteries. Atherosclerosis 2009; 207: 139-143.

[135] Yuan C, Polissar NL, Hatsukami TS. What will noninvasive carotid atherosclerosis imaging show us about high-risk coronary plaques? J Am Coll Cardiol 2011; 58: 423-5.

[136] Noguchi T, Yamada N, Higashi M, Goto Y, Naito H. High-intensity signals in carotid plaques on t1-weighted magnetic resonance imaging predict coronary events in patients with coronary artery disease. J Am Coll Cardiol 2011; 58: 416-22.

[137] Macedo R, Chen S, Lai S, et al. MRI detects increased coronary wall thickness in asymptomatic individuals: the multi-ethnic study of atherosclerosis (MESA). J Magn Reson Imaging 2008; 28: 1108-15.

[138] Miao C, Chen S, Macedo R, et al. Positive remodeling of the coronary arteries detected by magnetic resonance imaging in an asymptomatic population: MESA (Multi-Ethnic Study of Atherosclerosis). J Am Coll Cardiol 2009; 53: 1708-15.

[139] Delaney JAC, Scherzer R, Polak J, et al. Effect of inter-reader variability on outcomes in studies using carotid intima media thickness quantified by carotid ultrasonography. Eur J Epidemiol 2010; 25: 385-92.

[140] Espeland MA, Craven TTE, Riley WA, et al. Reliability of longitudinal ultrasonographic measurements of carotid intimal-medial thicknesses. Asymptomatic Carotid Artery Progression Study research group. Stroke 1996; 27: 480-5.
[141] Nicholls SJ, Hsu A, Wolski K, et al. Intravascular ultrasound-derived measures of coronary atherosclerotic plaque burden and clinical outcome. J Am Coll Cardiol 2010; 55: 2399-407.

[142] Nicholls SJ, Sipahi I, Schoenhagen P, et al. Application of intravascular ultrasound in anti-atherosclerotic drug development. Nat Rev Drug Discov 2006; 5: 485-92.

[143] Nissen SE, Yock P. Intravascular ultrasound: novel pathophysiological insights and current clinical applications. Circulation 2001; 103: 604-16.

[144] Nissen SE, Nicholls SJ, Sipahi I, et al. Effect of very high-intensity statin therapy on regression of coronary atherosclerosis: the ASTEROID trial. JAMA 2006; 295: 1556-65.

[145] Nissen SE, Tuzcu EM, Schoenhagen P, et al. Effect of intensive compared with moderate lipid-lowering therapy on progression of coronary atherosclerosis: a randomized controlled trial. JAMA 2004; 291: 1071-80.

[146] Finn AV, Chandrashekhar Y, Narula J. Seeking alternatives to hard end points. Is imaging the best APPROACH? Circulation 2010; 121: 1165-8.

[147] Lauer MS. Pseudodisease, the next great epidemic in coronary atherosclerosis? Arch Intern Med 2011; 171: 1268-9.

[148] Psaty BM. Drug therapies for the primary prevention of cardiovascular events: trials and errors: 2009 Ancel Keys memorial lecture. Circulation 2010; 121: 940-5.

[149] Weintraub WS, Diamond GA. Predicting cardiovascular events with coronary calcium scoring. N Engl J Med 2008; 358: 1394-6.

[150] Schwartz JS. Primary prevention of coronary heart disease with statins. It's not about the money. Circulation 2011; 124: 130-2.

[151] Lazar LD, Pletcher MJ, Coxson PG, Bibbins-Domingo K, Goldman L. Cost-effectiveness of statin therapy for primary prevention in a low-cost statin era. Circulation 2011; 124: 146-53.

[152] Goldfine AB, Kaul S, Hiatt WR. Fibrates in the treatment of dyslipidemias-time for a reassessment. N Engl J Med 2011; 365: 4814.

[153] Artinian NT, Fletcher GF, Mozaffarian D, American Heart Association Prevention Committee of the Council on Cardiovascular Nursing. Interventions to promote physical activity and dietary lifestyle changes for cardiovascular risk factor reduction in adults: a scientific statement from the American Heart Association. Circulation 2010; 122: 406-41.

[154] Juonala M, Magnussen CG, Venn A, et al. Influence of age on associations between childhood risk factors and carotid intima-media thickness in adulthood. The Cardiovascular Risk in Young Finns Study, the Childhood Determinants of Adult Health Study, the Bogalusa Heart Study, and the Muscatine Study for the International Childhood Cardiovascular Cohort (i3C) Consortium. Circulation 2010; 122: 2514-20.

[155] Heidenreich PA, Trogdon JG, Khavjou OA, et al. Forecasting the future of cardiovascular disease in the United States. A policy statement from the American Heart Association. Circulation 2011; 123: 933-44

[156] Mohlenkamp S, Lehmann N, Schmermund A, et al. Association of exercise capacity and the heart rate profile during exercise stress testing with subclinical coronary atherosclerosis: data from the Heinz Nixdorf Recall study. Clin Res Cardiol 2009;98:665-76.

[157] Mann KG. Thrombin generation in hemorrhage control and vascular occlusion. Circulation 2011; 124: 225-35.

[158] Mittleman MA, Mostofsky E. Physical, psychological and chemical triggers of acute cardiovascular events. Preventive strategies. Circulation 2011; 124: 346-54

[159] Bamberg F, Sommer WH, Hoffman V, et al. Meta-analysis and systematic review of the long-term predictive value of assessment of coronary atherosclerosis by contrast-enhanced coronary computed tomography angiography. J Am Coll Cardiol 2011; 57: 2426-36. 